\title{
TUMESCENT-ASSISTED ECHOSCLEROTHERAPY (TAES) IN THE TREATMENT OF GREAT SAPHENOUS VEIN INCOMPETENCE
}

\author{
Piotr Hawro ${ }^{1,2}$, Tomasz Urbanek2,3, Wojciech Mikusek ${ }^{1,2}$ \\ 'European Centre of Phlebology, Angelius Hospital, Katowice, Poland \\ 2Minimally Invasive Phlebology Centre AVIMED, Bytom, Poland \\ ${ }^{3}$ Department of General Surgery, Vascular Surgery, Angiology and Phlebology, Medical \\ University of Silesia, Katowice, Poland
}

\begin{abstract}
Objectives: Despite encouraging results of saphenous vein sclerotherapy this method is not free of potential complications and does not guarantee a $100 \%$ rate of occlusion. In this paper, the author's own experiences with catheter-directed, tumescent solution-supported echo-guided foam sclerotherapy of the saphenous vein are presented. Material and methods: Thirty-four incompetent great saphenous veins were treated with foam sclerotherapy involving the use of long catheters and perivenous tumescent solution injection prior to foam administration. The mean length of incompetent saphenous veins was $25.5 \mathrm{~cm}$ (range 14-39 $\mathrm{cm}$ ). The diameters of the proximal part of the saphenous veins ranged from 5.0 to $15.0 \mathrm{~mm}$. In 25 patients $(71.4 \%)$, primary varicose veins were diagnosed, and in other patients either post-surgical (recurrent) or post-thrombotic saphenous veins were treated.

Results: At 30-day follow up total occlusion of the entire segment of treated vein was achieved in $79.4 \%$ of cases. In one case the vein was not occluded, and in 6 patients $(17.6 \%)$ a partial occlusion was revealed. In the group of 6 patients with partial vein occlusion, a repeated sclerotherapy with the use of a short catheter and ultrasound guided puncture was performed. 6 and 12 months after the procedure, 32 out of 34 obliterated veins $(94.1 \%)$ remained fully occluded. The mean foam volume used for saphenous vein obliteration was $2.6 \mathrm{ml}$. No serious adverse events were reported.

Conclusions: Tumescent-assisted echo-guided foam sclerotherapy is a safe and clinically effective method of saphenous vein obliteration, particularly for veins with no history of a previous thrombosis or surgical treatment.
\end{abstract}

Key words: foam sclerotherapy, tumescent anesthesia, varicose vein treatment.
ORIGINAL PAPER

Phlebological Review 2017; 25, 1: 81-86

DOl: https://doi.org/10.5114/pr.2017.72537

Submitted: 3.12 .2017

Accepted: 14.12 .2017

\author{
ADDRESS FOR CORRESPONDENCE \\ Tomasz Urbanek \\ European Centre of Phleblogy \\ Fabryczna $13 \mathrm{D}$ \\ 40-635 Katowice, Poland \\ e-mail: urbanek.tom@interia.pl
}

\section{INTRODUCTION}

Progress related to the diagnostic and minimally invasive treatment of chronic venous diseases has led to significant improvement of the care of these patients. One of the most important steps towards modern phlebological treatment was the introduction of duplex Doppler diagnostic to the daily clinical practice [1]. Another factor that should be mentioned is sclerotherapy, which is currently used for the treatment of a wide range of venous pathologies [2]. Further progress basing on the implementation of endoluminal thermal and non-thermal ablation methods has increased the treatment possibilities and their efficacies.

Foam sclerotherapy was firstly described by S. McAusland in 1939 [3]. Another researcher who described the use of foam sclerotherapy for the treatment of reticular varicose veins was Robert Rowden Foote [4]. In 1956, Peter Fluckiger described the possibility of mechanical movement of the foam from the place of injection via manual compression and manipulation [5]. Over the years the method of foam production has been improved and established. Currently, the most commonly used method of foam production is the technique proposed by Lorenzo Tessari [6]. According to this method, two syringes are directly connected through three-way stopcock or a double syringe connector (DSS method). The proposed ratio of gas to liquid sclerosant ranges from $4: 1$ to $5: 1$, and various gas types have been investigated (air, $\mathrm{CO}_{2} / \mathrm{O}_{2}$ mixtures and $\mathrm{CO}_{2}$ ).

The implementation of ultrasound (US) examination not only improved diagnoses, but also led to clinical application of US examinations during sclerotherapy, including the US-guided foam sclerotherapy procedure. In 1968, Siegel from Philadelphia for the first time described continuous wave (CW) Doppler US for diagnosing venous system of the lower leg [7]. B mode US examination combined with CV Doppler for diagnosing the venous system 
of lower extremities was proposed for the first time by Day in 1976 [8]. In 1977 Franceschi documented the effect of calf compression and deep inspiration and expiration on venous flow in standing and recumbent positions, as well as the effect of Valsalva manoeuvre, and described the exploration of the veins with Doppler in normal subjects and varicose vein patients [9]. In 1982, Steve Talbot used Doppler US to confirm the role of Valsalva manoeuvre in the stimulation of venous flow changes in healthy veins. Talbot also confirmed the possibility of occlusion of venous lumen using a compression with sonographic probe [10]. In 1984 Effeney suggested that unchanged diameter of the vein during Valsalva manoeuvre is suggestive of the presence of thrombus inside venous lumen. In 1986, Ragavendra described clinical implementation of US-controlled compression test for the diagnosis of deep vein thrombosis [11]. In the same year Michel Schadeck published his experience with the use of US during foam sclerotherapy [12]. Sclerotherapy through a long catheter (with a liquid sclerosant) was presented for the first time by A. Gattoduring at the UIP World Congress in 1989 in Strasburg [13]. US-guided catheter-directed sclerotherapy was described in 1992 by Louis Grondin [14], and in 1995 Robert and Robert described the use of a dedicated catheter during the US-guided liquid sclerotherapy [15]. In 1997, the extended long-line echosclerotherapy method was proposed by Kurosh Parsi. In this method, following the cannulation of the saphenous vein, the tip of catheter is positioned $5 \mathrm{~cm}$ below the saphenofemoral junction, the leg is elevated at the angle of $45^{\circ}$, and liquid sclerosant is injected. The injection of the sclerosing agent causes visible turbulence on B-mode US, and also leads to an increased resistance against external compression of the vein wall following the procedure. In further studies, the catheter-directed US-guided sclerotherapy method was continuously modified and improved. Basing on experiences of Min and Navarro, the Seldinger method for venous access was proposed [16]. The implementation of perivenous tumescent infiltration aimed at external compression of the vein was firstly proposed by Thibault [17]. Milleret presented a similar technique augmented with an application of the Esmarck cuff in order to empty the vein prior to injection of the sclerosant [18]. The natural course of this research led to improved technique of sclerotherapy, such as foam sclerotherapy and the use of dedicated catheters, including balloon occlusive catheters $[19,20]$. In recent years, many papers have confirmed the simplicity and safety of catheter-guided sclerotherapy [21-23]. Cavezzi, searching for better results of foam sclerotherapy, described several sclerosing agent/gas mixtures [24]. The method of sclerotherapy through multiple short catheters has also been proposed $[25,26]$. In addition, Frullini presented the LAFOS method, basing on application of the holmium laser, which is used in order to shrink the vein before sclerotherapy [27]. A recent important modification of sclerotherapy com- prises mechanochemical endovenous ablation (MOCA) [28]. In this method mechanical irritation of venous wall results in its shrinkage, which enables administration of a reduced volume of sclerosing agent and eliminates the need for tumescent anaesthesia. The newest non-tumescent method for vein ablation comprises vein closure by intravenous application of a glue (cyanoacrylate) [29].

According to previous publications and authors' own experience, foam sclerotherapy can be used as a single treatment method, or in combination with surgical or endoluminal saphenous vein ablation [30-32]. In many cases foam sclerotherapy can be successfully used for complex treatments of pathologies of the entire superficial vein system, including obliteration of large veins and sclerotherapy of varicose veins. Regarding foam sclerotherapy treatment (including saphenous vein obliteration), both efficacy and safety have to be taken into consideration, especially if long vein segments or large veins need be ablated. The proper concentration of sclerosing agent and proper volume of injected foam are important factors that potentially can influence final outcome. According to current sclerotherapy guidelines (European Guidelines on Sclerotherapy), the maximum foam volume applied during one session should not exceed $10 \mathrm{ml}$, but this volume is not always sufficient to ablate long or large veins [33]. Alternatively to the use of MOCA, it is possible to administer tumescent solution around the treated vein in order to decrease volume of foam, which is needed for successful sclerotherapy. Potentially, an external compression along the entire vein can improve contact of foam with the venous wall (due to blood removal) and protect the sclerosant from being deactivated by blood compounds $[34,35]$. In this paper, the authors present their own experiences with US-guided, catheter-directed, tumescent supported foam obliteration (TAES) of incompetent saphenous veins.

\section{MATERIAL AND METHODS}

Thirty-four legs of 34 patients with incompetence of the great saphenous veins were treated with TAES and prospectively evaluated. The study was based on the prospective, non-interventional observation of the group of patients, who were managed using a standard treatment and follow up protocol applied in the European Centre of Phlebology in Katowice. All patients approved and signed the informed consent for standard treatment protocol and follow up. Data were prospectively and anonymously collected, without any integration into the patient treatment.

The group consisted of 26 female patients and 8 men. Mean age of patients was 47 years (19-72 years). Primary varicose veins were diagnosed in 25 patients $(71.4 \%)$. Other patients presented with recurrent varicose veins (5 cases) or varicose veins associated with a history of superficial thrombosis (4 cases). Mean length of incompetent 
saphenous vein was $25.5 \mathrm{~cm}$ (range: 14 to $39 \mathrm{~cm}$ ). Diameters of proximal parts of the saphenous veins ranged from 5.0 to $15.0 \mathrm{~mm}$ (mean: $6.97 \mathrm{~mm}$ ), and distal diameters (at the lowest point of reflux) ranged from 5 to $8 \mathrm{~mm}$ (mean: $5.65 \mathrm{~mm})$. A significant percentage of patients presented with concomitant morbidities (Table 1). In addition, 4 female patients received hormonal replacement therapy.

Duplex Doppler US examinations of the venous system were performed in all patients. Majority of patient presented with class $\mathrm{C} 2$ and $\mathrm{C} 3$ of the CEAP classification and only a few with more advanced disease (Fig. 1). Exclusion criteria comprised: active venous thromboembolism, known allergic reactions to polidocanol or lidocaine, previous endovenous thermal or non-thermal ablation of varicose veins, known arteriovenous shunts, pregnancy, obstructive changes or occlusions in the deep venous system, significant leg ischemia (ABI $<0.8$ ), recent ( $<12$ months) superficial vein thrombosis, known contraindications to compression therapy.

\section{Procedure description}

The treatments were performed under US guidance. The vein puncture was localised in the lowest point of truncal reflux, and after administration of local anaesthesia ( $1 \%$ lidocaine), vein puncture with an $18-\mathrm{G}$ needle was performed. A 0.035 " guidewire was introduced and a $4 \mathrm{~F}$ straight catheter was inserted into the vein lumen. The tip of catheter was placed $3 \mathrm{~cm}$ below the saphenofemoral junction, and the guidewire was removed. The position of the tip of catheter was controlled using US. After catheter positioning, the tumescent solution was injected into the perivenous space. The following tumescent solution mixture was used: lidocaine $-1 \mathrm{~g} / \mathrm{l}$; epinephrine $1 \mathrm{mg} / \mathrm{l} ; 8.4 \%$ sodium bicarbonate $-10 \mathrm{mEq} / \mathrm{l}$ and $0.9 \%$ $\mathrm{NaCl}$ up to the volume of $1000 \mathrm{ml}$. The pump was used for injection of tumescent solution and $10 \mathrm{~mL}$ of solution per $1 \mathrm{~cm}$ of the treated vein was injected (the injection of tumescent solution was US-controlled to confirm complete compression of the vein around the catheter). After compressing the vein and the check of the position of catheter tip, 3\% polidocanol foam was injected. The foam was prepared according to the Tessari method. The velocity of the injection depended on US control. During the injection the traction of the catheter was US-controlled in order to fill the target vein lumen with foam but not moving it (except for single foam bubbles) into the deep vein system. The foam volume of each procedure was recorded. After foam injection and catheter removal, access area was covered with sterile dressings and class 2 thigh compression stocking was worn, with recommendation of applying stockings for 4 weeks. Then the patients were mobilised and discharged. At follow-ups, which were performed 1, 6, 12 and 18 months after sclerotherapy, patients were assessed clinically and with the use of US. Total occlusion was defined as an occlusion of the entire
Table 1. Concomitant diseases

\begin{tabular}{ccc}
\hline & & \\
\cline { 2 - 3 } & No of patients. & $\%$ \\
\hline Ischaemic heart disease & 12 & 35.3 \\
\hline Arterial hypertension & 15 & 44.1 \\
\hline Diabetes mellitus & 4 & 11.8 \\
\hline Obesity & 8 & 23.5 \\
\hline Osteoarticular degenerative disease & 8 & 23.5 \\
\hline
\end{tabular}

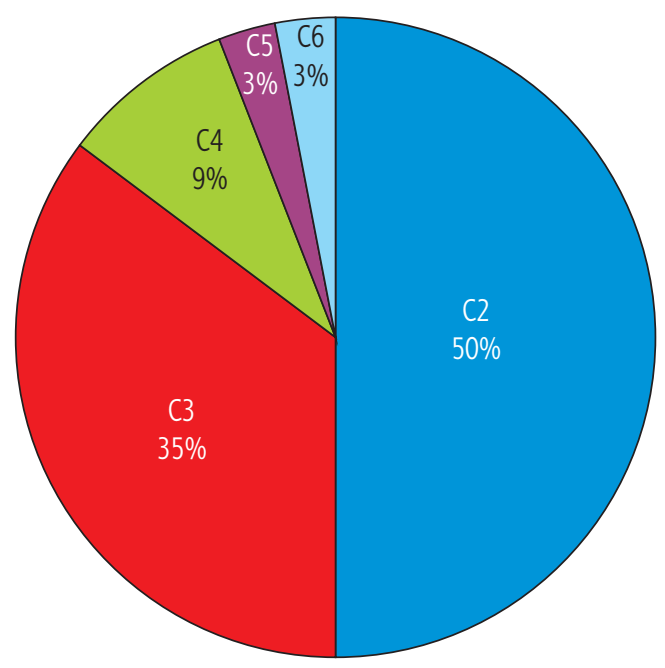

Fig. 1. C class of the CEAP classification in the treated group

length of target vein from the access area to the saphenofemoral junction. Partial occlusion was defined as a lack of full occlusion of the entire length of the treated venous segment (a presence of patent segments between the occluded proximal or distal parts of the treated vein). In all cases the management of non-saphenous varicose veins with sclerotherapy was postponed until occlusion of the saphenous vein was confirmed at a follow up.

The Statistica 10 software package was used for statistical analysis. In order to identify factors that potentially were responsible for unsuccessful treatment we applied the multiple regression analysis.

\section{RESULTS}

We injected $1.5-4 \mathrm{ml}$ of $3 \%$ polidocanol during sclerotherapy; mean volume of foam was $2.6 \mathrm{ml}$. No serious advert events, including neurological or ophthalmological symptoms potentially related to the administration of foam, were reported. No symptomatic or asymptomatic DVT were diagnosed at follow up.

One month after the procedure a complete occlusion of the entire segment of target vein was confirmed in $79.4 \%$ of cases (27 out of 34 veins). In one case (2.9\%), the vein was still patent and partial occlusion was observed in 


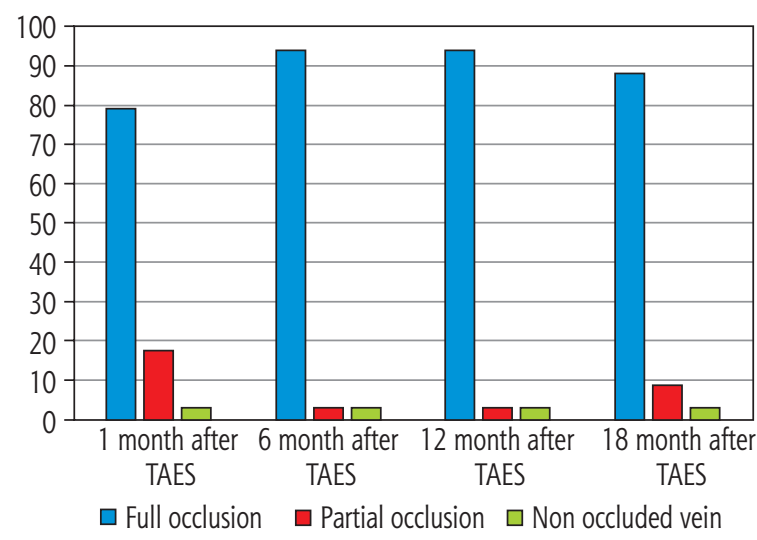

Fig. 2. Success rate 1, 6, 12 and 18 months after TAES of the great saphenous vein (34 treated veins)

6 patients (17.6\%). In the group of 6 patients with partial occlusion, 1 month after the first intervention we performed another foam sclerotherapy, using a direct puncture of the vein under US control. For this purpose we used 1-3 mL of $3 \%$ polidocanol (mean: $2.33 \mathrm{~mL}$ ). Out of these patients, 5 developed full obliteration of the target vein, and 1 patient only partial occlusion, with a $12-\mathrm{cm}$ long segment of non-occluded vein. One patient with completely failed first session of sclerotherapy did not consent for further treatment with this method. At follow ups 6 and 12 months after the procedure, 32 out of 34 obliterated veins $(94.1 \%)$ remained fully occluded. There were 2 additional cases of partial recanalisation at 18-month follow up (Fig. 2).

We also analysed patients with non-occluded and partially occluded veins after the first session of sclerotherapy. The patient with failed sclerotherapy had a history of previous thrombosis of the saphenous vein. In the group of patients with partial recanalisation (6 individuals), 2 of them presented with recurrent varicosities after surgical treatment, while 2 patients had a history of thrombosis of the saphenous vein. Technical success of sclerotherapy after 1 session of treatment in patients without a history of previous saphenous vein surgery or thrombosis was $92 \%$. Other clinical factors evaluated by means of multivariate analysis, such as patient's age, duration of the disease, $\mathrm{C}$ class of the CEAP classification, length of the target vein and its diameter were not found to be statistically significant.

We also evaluated the cost of procedure. An average cost of medications and disposables was 25 euro per patient.

\section{DISCUSSION}

According to the results of our study a high efficacy and safety of TAES, combined with a low cost of this procedure, justifies its use as the cost-effective method for the treatment of the saphenous vein incompetence.
The concept of application of tumescent solution perivenously is currently well known and widely used during treatment of patients managed with thermal ablations. As has been previously mentioned, the use of tumescent solution was also proposed to augment sclerotherapy $[34,35]$. A fluid injected perivenously compresses the vein, removes blood from its lumen and leads to significant shrinking of the target vein that allows a reduction of foam volume. These factors, at least theoretically, can result in a higher efficacy and safety of the treatment. Still, high quality studies confirming efficacy and safety of TAES in clinical practice have not yet been released $[17,30,34,35]$. Sclerotherapy is a standard phlebological procedure [33] and combined treatment (foam sclerotherapy with the application of perivenous tumescent solution) seems to be an interesting alternative for more technically complex and more expensive methods, such as RF and EVLT. In our patient series $94.1 \%$ of the managed saphenous veins remained fully occluded at 6- and 12-month follow ups. A majority of failed treatments occurred in patients with a history of saphenous thrombosis or previous varicose vein surgery. Still, a redo sclerotherapy resulted in complete closure of target veins in most of these patients. Moreover, final results at 1-, 6- and 12-month follow ups, including reinterventions, were similar in patients with and without a history of previous thrombosis or surgery. This finding, together with a relatively low cost of the procedure (25 euro per session of TEAS) suggests that this method is an interesting alternative to more sophisticated treatment modalities, especially in patients with no history of thrombosis or surgical treatment for varicose veins [31].

A high safety of TEAS should also be emphasised. We did not observe any serious adverse events, which was potentially due to the following factors: reduced foam volume (mean volume of foam required for obliteration of the saphenous vein was $2.6 \mathrm{ml}$, and maximal volume in the case of a $39-\mathrm{cm}$ long vein was $4 \mathrm{ml}$ ), emptying of the vein, which decreases the amount of blood inside its lumen and potentially diminished risk of foam migration related to compression of the venous lumen. At follow ups no deep venous thromboses were diagnosed, despite the fact that 8 saphenous veins were larger than $8 \mathrm{~mm}$ in diameter.

Studies on sclerotherapy suggest that early recanalisations are related to the large diameters of the vein. This phenomenon can be explained by possible deactivation of sclerosing agent by blood present in the venous lumen $[31,33]$. An application of tumescent solution leads to emptying of the vein, which together with vasoconstrictive activity of epinephrine improves final results of the treatment $[29,33,34]$.

Currently only one controlled randomised study on TAES has been published. Devereux and co-workers did not demonstrate an advantage of application of tumescence solution during foam sclerotherapy of the great 
saphenous vein performed through a long catheter [33]. Still, some of the methods used in this study have to be challenged, particularly the fact that a $0.9 \%$ tumescent solution without epinephrine was injected, which potentially could negatively influenced final results. Epinephrine is one of the components of a standard tumescent anaesthesia. Rationale of its use is to decrease absorption of the tumescent solution and to prolong and enhance vasoconstriction of the vein. This issue was addressed by Cavezzi in the discussion on the results of the Devereux's study [35]. Thus, we need another prospective randomised clinical trial to evaluate the actual efficacy of TAES.

\section{CONCLUSION}

Tumescent-assisted echo-guided foam sclerotherapy is a safe and clinically effective method for obliteration of the saphenous vein, particularly in patients with no previous history of superficial venous thrombosis or surgical treatment of varicose veins.

The author declares no conflict of interest.

\section{References}

1. Hawro P., Gabriel M., Madycki G., Kuczmik W., Urbanek T. Zalecenia dotyczące wykonywania ultrasonograficznego badania dopplerowskiego żył kończyn dolnych Polskiego Towarzystwa Chirurgii Naczyniowej i Polskiego Towarzystwa Flebologicznego. Acta Angiol 2013; 19: 99-117.

2. O'Flynn N., Vaughan M., Kelley K. Diagnosis and management of varicose veins in the legs: NICE guideline. Br J Gen Pract 2014; 64: 314-315.

3. McAusland S. The modern treatment of varicose veins. Med Press Circular 1939; 201: 404-410.

4. Foot R.R. The injection treatment. In: Foote R.R. (ed.). Varicose veins, haemorrhoids and other conditions. Lewis, London 1944 13-44.

5. Fluckiger P. Nicht-operative retrograde Varicenverodung mit Varsylschaum. Schweiz Med Wochenschr 1956; 86: 1368-70.

6. Cavezzi A, Frullini A, Ricci S, Tessari L. Treatment of varicose veins by foam sclerotherapy: two clinical series. Phlebology 2002; 17: 13-18.

7. Sigel B., Popky G.L., Wagner D.K., Boland J.P., Mapp E.M., Feigl P. Comparison of clinical and Doppler ultrasound evaluation of confirmed lower extremity venous disease. Surgery 1968; 64 : 332-338.

8. Day T.K., Fish P.J., Kakkar W. Detection of deep vein thrombosis by Doppler angiography. Br Med J 1976; 1: 618-20.

9. Franceschi C. L'investigation vasculaire par ultrasonographie Doppler. Masson edit. Paris, 1977.

10. Talbot S.R. Use of real-time imaging in identifying deep venous obstruction: a preliminary report. Bruit 1982; 7: 41-2.

11. Cronan J.J. History of Venous Ultrasound. J Ultrasound Med 2003; 22: 1143-1146.

12. Schadeck M. Doppler et Echotomographie dans la sclerose des veines saphe'nes. Phlebologie 1986; 39: 697-716.
13. Gatto A. La sclerose de la saphene interne jusqua la crosse avec catheter (video). In: Davy A., Stemmer R. (eds.). Phlebologie. John Libbey Eurotext Ltd, 1989; 797.

14. Grondin L., Soriano J. Duplex-echosclerotherapy, the quest for the safe technique. Phlebologie. John Libbey, Paris 1992: 824-5.

15. Robert C., Robert J.L. La sclerose par echo-catheterisme. Phlebologie 1995; 48: 13-16.

16. Min R.J., Navarro L. Transcatheter duplex ultrasoundguided sclerotherapy for treatment of greater saphenous vein reflux: preliminary report. Dermatol Surg 2000; 26: 410-4.

17. Thibault P. Internal compression (peri-venous) following ultrasound guided sclerotherapy to the great and small saphenous veins. Aust NZ J Phleb 2005; 9: 29-32.

18. Milleret R., Garandeau C., Brel D., Allaert F.A. Foam sclerotherapy of the great saphenous veins via ultrasound-guided catheter in an empty vein: the alpha-technique. Phlebologie 2004; 57: 15-18.

19. Bidwai A., Beresford T., Dialynas M., Prionidis J., Panayiotopoulos Y., Bowne T.F. Balloon control of the saphenofemoral junction during foam sclerotherapy: proposed innovation. J Vasc Surg 2007; 46: 145-7.

20. Brodersen J.P. Catheter-assisted vein sclerotherapy: a new approach for sclerotherapy of the greater saphenous vein with a double-lumen balloon catheter. Dermatol Surg 2007; 33: 469-75.

21. Wildenhues B. Catheter-assisted foam sclerotherapy: a new minimally invasive method for the treatment of trunk varicosis of the long and short saphenous veins. Phlebologie 2005; 34: 165-170.

22. Hahn M., Schulz T., Junger M. Sonographically guided, transcatheter foam sclerotherapy of the great saphenous vein; medical and oeconomic aspects. Phlebologie 2007; 36: 309-312.

23. Kolbel T., Hinchliffe R.J., Lindbal B. Catheter-directed foam sclerotherapy of axial saphenous reflux: early results. Phlebology 2007; 22: 219-222

24. Cavezzi A., Tessari L. Foam sclerotherapy techniques: different gases and methods of preparation, catheter versus direct injection Phlebology 2009; 24: 247-251.

25. Jaworucka-Kaczorowska A., Jaworucki M. Echoskleroterapia piankowa przy użyciu venflonów wspomagana tumescencją w leczeniu przewlekłej niewydolności żyły odpiszczelowej. Phlebol Rev 2013; 21: 28.

26. Parsi K., Exner T., Connor D.E., Herbert A., Ma D.D.F., Joseph J.E. The lytic effects of detergent sclerosants on erythrocytes, platelets, endothelial cells and microparticles are attenuated by albumin and other plasma components in vitro. Eur J Vasc Endovasc Surg 2008; 36: 216-223.

27. Frullini A., Fortuna B. Laser assisted foam sclerotherapy (LAFOS): a new approach to the treatment of incompetent saphenous veins. Phlebologie 2013; 66: 51-54.

28. Elias S., Lam Y.L., Wittens C.H. Mechanochemical ablation: status and results. Phlebology 2013; 28 (Suppl 1): 10-14.

29. Guex J.J. Endovenous chemical (and physical) treatments for varices: what's new? Phlebology 2014;29 (Suppl 1): 45-48.

30. Cavezzi A., Mosti G., Di Paolo S., Tessari L., Campana F., Urso S.U. Ultrasound-guided perisaphenous tumescence infiltration improves the outcomes of long catheter foam sclerotherapy combined with phlebectomy of the varicose tributaries. Veins Lymphatics 2015; 4: 4676.

31. Gohel M. Which treatments are cost-effective in the management of varicose veins? Phlebology 2013; 28 (Suppl 1): 153-7. 
Piotr Hawro, Tomasz Urbanek, Wojciech Mikusek

32. Nesbitt C., Eifell R.K., Coyne P., et al. Endovenous ablation (radiofrequency and laser) and foam sclerotherapy versus conventional surgery for great saphenous vein varices. Cochrane Database Syst Rev 2011; 10: CD005624.

33. Rabe E., Breu F.X., Cavezzi A., et al. European guidelines for sclerotherapy in chronic venous disorders. Phlebology 2014; 29: 338-354.

34. Devereux N., Recke A.L., Westermann L., Recke A., Kahle B. Catheter-directed foam sclerotherapy of great saphenous veins in combination with pre-treatment reduction of the diameter employing the principals of perivenous tumescent local anesthesia. Eur J Vasc Endovasc Surg 2014; 47: 187-195.

35. Cavezzi A., Mosti G., Di Paolo S., Tessari L., Campana F., Urso S.U. Re: catheter-directed foam sclerotherapy of great saphenous veins in combination with pre-treatment reduction of the diameter employing the principals of perivenous tumescent local anesthesia. Eur J Vasc Endovasc Surg 2014; 48: 597. 